\title{
Teaching learners to appropriately mitigate requests
}

\author{
Esther Usó-Juan and Alicia Martínez-Flor
}

\begin{abstract}
It is commonly recognized that, for lecturers of English as a Foreign Language (EFL) in a university setting, the goal of their teaching of is to develop learners' ability to communicate appropriately in this language. This means that teaching practices should pay attention not only to the key features of the linguistic system of English, but also to its pragmatic norms since lack of this knowledge may impede communication. Consequently, language learners need to be exposed to appropriate input in the classroom. In order to help lecturers in this task, it is the aim of this paper to present a learner-based instructional method designed to develop learners' pragmatic ability when using request mitigating devices in EFL. The rationale behind the selection of this pragmatic feature is discussed in the paper together with an explanation of the proposed teaching method.
\end{abstract}

\section{Introduction}

Why do learners often experience difficulties when trying to communicate in EFL? How can we teach them to overcome those communication difficulties? These are important questions to be answered to help teachers develop their learners' full communicative competence. To that end, this paper is divided into two major parts: first, we address the importance of tackling pragmatics in the EFL classroom by focusing specifically on the speech act of requesting and its mitigating devices. Reasons behind the selection of this particular pragmatic feature are provided; second, we present a learner-based instructional method to facilitate the teaching of that particular speech act, and consequently help learners to communicate successfully in English. 


\section{Pragmatic competence}

In response to the first question, 'Why do learners often experience difficulties when trying to communicate in EFL?', it has been claimed that for learners to become communicatively competent, they need to possess not only knowledge of the grammatical and lexical systems but also of the social and contextual factors underlying the English language. These factors refer to those norms of interaction that are shared by members of a given speech community in order to establish and maintain successful communication. They are related to one of the vital components of the construct of communicative competence, that is pragmatic competence (Bachman 1990). Pragmatic competence involves speakers' ability to employ different linguistic formulae in an appropriate way when interacting in a particular social and cultural context. A lack of this competence on the part of learners may result in misunderstandings that can subsequently provoke a breakdown of communication. Consequently, learners need to be made aware of the importance of behaving in an appropriate way when using a variety of pragmatic features if their goal is to achieve full and successful communication in the English language and culture. Among those pragmatic features, the speech act of requesting is one where learners need a great deal of expertise in order to avoid communication problems.

\section{The speech act of requesting: a focus on its mitigating devices}

A request has been defined as a directive speech act in which the speaker asks the hearer to perform an action which is for the exclusive benefit of the speaker (Trosborg 1995). Therefore, requests have been considered as one of the most face-threatening speech acts in Brown and Levinson's (1987) politeness theory, since they intrinsically threaten the hearer's face. This speech act can be performed by using three main types of realization strategies, namely direct (for example, 'Give me some money'), conventionally indirect (for example, 'Could you give me some money?') and indirect strategies (for example, 'I need to make a telephone call'). The three of them have the function of requesting and can stand by themselves, which is why they have been referred as the core or head act of the request. However, given the nature of this speech act 
as an imposition, it is usually necessary to soften the impact it may have on the hearer by means of using the indirect strategies rather than direct or conventionally indirect ones. In this way, the requester may save face and avoid communication problems, since the use of indirect strategies gives the impression that the hearer has more freedom to comply or not with the request being made. In addition to minimizing the face-threatening nature of requests via indirectness, the requester may also resort to the use of some specific mitigating devices. These devices, which have also been regarded as part of this speech act, refer to optional elements that may follow and/or precede the request head act (for example, 'Excuse me, could you give me some money, please?').

\section{Types and functions of request mitigating devices}

The mitigating devices can be divided into two main types, namely internal and external. The former refer to those devices that appear within the request head act itself, whereas the latter involve the use of devices that occur in the immediate linguistic context surrounding the request head act. It should be noted that the individual types and functions of internal and external mitigating devices differ among the classification schemes presented in the literature since this is an inherently fuzzy area of language. However, some kind of workable systematization of those devices is needed for pedagogic purposes. Therefore, the following analytical scheme which is supported by examples extracted from film excerpts (Martínez-Flor 2007) could be of help for language teachers. This classification is founded on empirical investigations carried out in the fields of interlanguage (Trosborg op. cit.; Nikula 1996; Achiba 2003) and cross-cultural pragmatics (House and Kasper 1981; Sifianou 1999). Starting with the internal mitigating devices, three subtypes have been outlined:

1 openers: i.e. opening items and expressions that introduce the intended request (for example, 'Gentlemen, would you mind leaving us, please?')

2 softeners: i.e. items that soften the impositive force of the request (for example, 'Listen, can I talk to you for a second?'; 'If you could possibly return this to Fred's for me, please.')

3 fillers: i.e. items, such as hesitators (for example, 'er', 'erm'), cajolers (for example, 'you know, you see, I mean'), appealers (for example, 'OK?', 'right?’) or attention-getters (for 
example, 'excuse me', 'hello', 'Mr. Smith?'), that fill in gaps in the interaction (for example, 'Excuse me, can you tell me how to get to Beverly Hills?'; 'Oscar, lower it a bit, would you?’)

Regarding the external mitigating devices, five subtypes have been identified:

1 preparators: i.e. devices that prepare the addressee for the subsequent request (for example, 'Colonel, I do have to ask you a couple of questions about September the $6^{\text {th }}$.')

2 grounders: i.e. devices that give reasons that justify the request (for example, 'Call my family, I'd like them to have dinner with me tonight.')

3 disarmers: i.e. devices that are employed to avoid the possibility of a refusal (for example, 'Colonel Jessep, if it's not too much trouble, I’d like a copy of the transfer order, Sir.')

4 expanders: i.e. devices related to repetition that are used to indicate tentativeness (for example, 'Can you take him to the airport in the morning? ... can you pick him up at 8.30 ?’)

5 promise of a reward: i.e. devices that are used by the requester so that his/her request may be accomplished (for example, '...she wants a bottle of wine ... I would promise to send you the money.')

Additionally, 'please' can also be considered another type of mitigating device, which among other functions, it is used to signal politeness (for example, 'Would you hang up please and I'll call your machine?'). All the above mitigating devices can be employed to minimize the impact a request may have on the hearer. Therefore, learners' knowledge of these mitigating devices is vital to help them to perform socially appropriate requests for successful communication. However, given the fact that several mitigating devices can be chosen for the same type of situation, learners need to know how interactional and contextual factors affect the choice of a particular pragmalinguistic form for these devices. 


\section{Interactional and contextual factors}

Being aware of the social and cultural context in which a particular communicative situation takes place, as well as the participant relationship observed in such a situation is of paramount importance for a pragmatically appropriate use of request mitigating devices (Nikula op. cit.). More specifically, attention needs to be drawn to those interactional and contextual factors illustrated in Brown and Yule's (1983) discourse interaction types, and Brown and Levinson's (op. cit.) politeness theory. On the one hand, Brown and Yule (op. cit.) distinguish two main types of interaction that affect an appropriate requestive behavior, namely transactional and interactional. The former refers to that kind of interaction in which the request is merely made to transmit information and therefore does not need to be softened (for example, a police officer's direct order to a subordinate during a car accident). The latter involves a sort of interaction in which the request is performed to establish and maintain relationships and consequently, it is usually mitigated since the speaker may place an imposition on the hearer (for example, a conversation between friends). On the one hand, the three sociopragmatic parameters identified by Brown and Levinson (op. cit.) are also important to perform an appropriate request. These factors involve power, which refers to the social status of the speaker with reference to the hearer (for example, boss-employee, teacher-student), social distance, which is related to the degree of familiarity between interlocutors (for example, close friends versus strangers), and rank of imposition, which concerns the type of imposition the speaker is exerting over the hearer (for example, asking for a pen versus asking for a huge amount of money).

Given the importance of these factors, learners need to be aware of them in order to overcome particular problems when communicating in EFL. In instructional settings, learners often lack the opportunities to be exposed to this kind of sociopragmatic information since teaching syllabi are centred on textbooks, which have been criticized for presenting isolated and descontextualised examples of communicative situations. (See Usó-Juan 2007 for a review.) This fact could be therefore the response to the first question guiding this paper in those particular situations in which requesting for something is the main goal of the communicative situation. As a consequence, language teachers should integrate pragmatics in the classroom so that learners can be provided with the necessary tools to deal with communication difficulties. 


\section{A learner-based method for teaching request mitigating devices}

Let us now consider the second question, that is 'How can we teach learners to overcome communication difficulties in EFL?' Researchers in the field of interlanguage pragmatics have proposed different approaches and activities to foster learners' pragmatic competence (Olshtain and Cohen 1991; Judd 1999; Rose 1999). Taking suggestions from this research into account, we have devised a learner-based instructional method to specifically teach learners request mitigating devices and, subsequently, aid them in overcoming difficulties in communicative situations. The method consists of three main stages: learners' exploration, learners' production and learners' feedback. Each stage is explained briefly along with samples of activities to be implemented and practiced in the EFL classroom.

\section{Learners' exploration}

In this first stage, learners are provided with opportunities to explore the pragmalinguistic forms and the sociopragmatic factors that influence the appropriateness of request mitigating devices. This step aims at making learners aware of: (i) cross-linguistic and cross-cultural differences between their native language and the English language, and (ii) the crucial role pragmatic issues play in communicative situations (Usó-Juan op. cit.). Here two types of awareness raising activities are proposed. As regards the first type of activities, one technique that has worked well with our learners is to make them think of naturally occurring requests they perform daily in their mother tongue. For this activity, learners are provided with a worksheet that includes pragmalinguistic and sociopragmatic awareness-raising questions to help them analyse their own samples—see Figure 1.

\section{[INSERT FIGURE 1 HERE]}

Once learners have analysed samples from their mother tongue, the teacher guides them in exploring samples in English. In such an activity, examples from film scenes can be used as a rich source of pragmatic input that shows learners a variety of request mitigating devices in different contextualized situations. (See Martínez-Flor (op. cit.) for contextualized samples in film scenes of the request mitigating devices previously presented.) Moreover, the potential of using film excerpts is that it allows learners to observe aspects of the characters' non-verbal behavior that play an important role in the successful completion of the request (for example, 
tone of the voice, body language, attitudinal behavior, facial expressions, and so on). Needless to say, samples from authentic situations in English should be presented to learners when possible. With a careful and appropriate choice of this material, this practice can awaken learners' interest in the activities that follow.

With regard to the second type of awareness-raising activities, a variety of techniques are recommended. In an attempt to widen the scope of the request mitigating devices presented in textbooks - see Usó-Juan (op. cit.) for the limited range of forms presented in this types of materials-learners are asked to read a language situation containing a rich source of pragmatic information, and three request responses to that situation. The requests can be presented on a directness scale and mitigated in a variety of ways, for example: (i) internally (for example, ' $D o$ you mind opening the door?'), (ii) externally (for example, 'It seems it is quite hot here. Could you open the door?'), and (iii) doubly modified, internally and externally (for example, 'I hate bothering you but could you just open the door?'). Learners then have to rank the responses from the most to the least appropriate in each situation applying the principles discussed in the first activity. Another simple activity is to give learners the whole context of a situation and a request, which can be mitigated or not, for response to it and then ask them to rate which they believe is the level of suitability on a scale ranging from 1 to 5 , as well as give the reason why they provide that particular rating.

In addition, film excerpts can also be of great help in increasingly raising learners' pragmatic awareness (Rose op. cit.; Martínez-Flor op. cit.). By way of example, learners can be invited to watch two scenes in a film in which characters are interacting in two contrasting situations depicting a suitable context for a request. After watching the two scenes, learners are asked to conduct an analysis of the pragmalinguistic and sociopragmatic features of the two scenarios by completing a video worksheet-see Figure 2. A key aspect of this activity is to allow learners time for pragmatic reflection. Therefore, the two scenes should be viewed as many times as needed.

\section{[INSERT FIGURE 2 HERE]}

On the whole, the main pedagogic purpose of this first stage is to draw learners' attention to the connections between request pragmalinguistic patterns and sociopragmatic information. Once an understanding of this relationship is achieved, learners are ready to engage in communicative 
practice, which is the aim of the next stage.

\section{Learners' production}

In this second stage, learners are provided with written and oral opportunities to produce request head acts and their mitigating devices. Regarding written opportunities, the activity of writing emails is strongly encouraged here. As noted by Judd (op. cit.), it is of paramount importance to provide learners with contrasting scenarios, that is with scenarios that differ in sociopragmatic features. Therefore, they are asked to write an email to a friend borrowing a course book (i.e. low imposition) and/or borrowing the car (i.e. high imposition); and to a professor asking for an appointment to talk about a topic for the term paper (i.e. low imposition) and/or asking for the favour of postponing the exam date (i.e. high imposition). This activity can work even better if learners are taken to the computer lab to send emails to addressees created on purpose for this activity.

As regards oral practice opportunities, role-play activities are particularly suitable here. One activity involves the use of the DVD. The teacher selects two different scenes from a film in which characters are interacting in two different requesting situations. These situations are played and when the requests are about to be elicited, the video scenes are paused and learners have to role-play how they think the two conversations are likely to follow (Martínez-Flor op. cit.). After learners' performance, the two video scenes are played again from the beginning to the end in an attempt to allow learners to compare the requests, with their accompanying mitigating devices employed in the film with the ones they have produced. Additionally, an interesting follow-up activity requires learners to perform the same role-plays again but this time the interactional and contextual variables are diametrically opposed to the ones already watched in the film and acted out. As learners become more aware of how these situational variables affect the choice of the pragmalinguistic form, the teacher's guidance in those explanations should be minimized to allow them experience in free written and spoken activities (Judd op. cit.).

\section{Learners' feedback}

In the third and final stage, learners are provided with feedback from their peers about their 
performance in the communicative practice activities in terms of the pragmalinguistic forms selected to express their request head acts and their mitigating devices, as well as the sociopragmatic factors considered appropriate for a requestive performance in the given situations (Olshtain and Cohen op. cit.). Such feedback, and further discussion with the rest of the class as well as the teacher's comments on both the feedback provided by the learners and the whole teaching approach is essential to help learners use more appropriate request head acts and mitigating devices.

\section{Conclusion}

In this paper we have tried to explain why learners may experience communication difficulties in EFL, and how those difficulties may be overcome by tackling pragmatics in the classroom. Specifically, we have focused on the particular speech act of requesting, as an example of a pragmatic feature that requires a great deal of expertise on the part of the learners in order to achieve full communication. Given the face-threatening nature of this speech act, in the first part of this paper we have addressed the importance of employing mitigating devices when requesting. The variety of types and functions that these devices can adopt has been presented, and the importance of considering the interactional and contextual variables in which they take place has been discussed. Following this, a learner-based instructional method aimed at integrating pragmatics in the classroom with a particular focus on request mitigating devices has been proposed. Although such as a method deals specifically with the speech act of requests, it could easily be adopted for the teaching of other speech acts, as for example suggestions, apologies, or refusals. Additionally, it should be noted that the instructional approach described has been particularly devised for its implementation in EFL classrooms by supporting the view that language and culture go hand in hand. However, this issue has recently been considered as problematic if we consider the use of English as a lingua franca (ELF). Therefore, it would be very interesting to conduct research on how the pragmatics of ELF could be incorporated in current teaching practices or whether the suggested instructional method presented here could be of help in achieving that aim. In the meantime and to sum up, we believe that our practical teaching approach may provide teachers and learners with deeper insights into the process of becoming communicatively competent in an EFL context. 


\section{Note}

This study is part of a research project funded by (a) the Spanish Ministerio de Educación y Ciencia (HUM2004-04435/FILO), co-funded by FEDER, and (b) Fundació Universitat Jaume I and Caixa Castelló-Bancaixa (P1.1B2004-34).

\section{References}

Achiba, M. 2003. Learning to Request in a Second Language: Child Interlanguage Pragmatics. Clevedon: Multilingual Matters.

Bachman, L. F. 1990. Fundamental Oonsiderations in Language Testing. Oxford: Oxford University Press.

Brown, G. and G. Yule. 1983. Teaching the Spoken Language. Cambridge: Cambridge University Press.

Brown, P. and S. Levinson. 1987. Politeness: Some Universals in Language Use. Cambridge: Cambridge University Press.

House, J. and G. Kasper. 1981. 'Politeness markers in English and German' in F. Coulmas (ed.). Conversational Routine. The Hague: Mouton de Gruyter.

Judd, E. L. 1999. 'Some issues in the teaching of pragmatic competence' in E. Hinkel (ed.). Culture in Second Language Teaching and Learning. Cambridge: Cambridge University Press.

Martínez-Flor, A. 2007. 'Analysing request modification devices in films: implications for pragmatic learning in instructed foreign language contexts’ in E. Alcón and P. Safont (eds.). Intercultural Language Use and Language Learning. The Netherlands: Springer.

Nikula, T. 1996. Pragmatic Force Modifiers. A Study in Interlanguage Pragmatics. Jyväskylä: University of Jyväskylä.

Olshtain, E. and A. D. Cohen. 1991. 'Teaching speech act behavior to nonnative speakers' in M. CelceMurcia (ed.). Teaching English as a Second or Foreign Language. Boston: Heinle and Heinle.

Rose, K. R. 1999. 'Teachers and students learning about requests in Hong Kong' in E. Hinkel (ed.). Culture in Second Language Teaching and Learning. Cambridge: Cambridge University Press.

Sifianou, M. 1999. Politeness Phenomena in England and Greece. A Cross-cultural Perspective. Oxford: 
Oxford University Press.

Trosborg, A. 1995. Interlanguage Pragmatics. Requests, Complaints and Apologies. Berlin: Mouton de Gruyter.

Usó-Juan, E. 2007. 'The presentation and practice of the communicative act of requesting in textbooks: focusing on modifiers' in E. Alcón and P. Safont (eds.). Intercultural Language Use and Language Learning. The Netherlands: Springer.

\section{The authors}

Dr Esther Usó-Juan and Dr Alicia Martínez-Flor are professors in Applied Linguistics in the Department of English Studies, Universitat Jaume I of Castellón, Spain, where they teach both undergraduate and postgraduate courses in EFL teaching methodology. Their research focuses on interlanguage pragmatics, as well as the learning and teaching of the four language skills from a communicative perspective.

Emails: euso@ang.uji.es aflor@ang.uji.es 
Pragmalinguistic questions

- How many request head acts have you thought of?

- How many request mitigating devices have you thought of?

- $\quad$ Can you arrange the request head acts on a directness scale?

- $\quad$ Can you organize the request mitigating devices according to their types and functions?

Sociopragmatic questions

- Which different request head acts and mitigating devices have you found depending on the degree of familiarity that exists between the speakers?

- Which different request head acts and mitigating devices have you found depending on the speaker's power over the hearer?

- Which different request head acts and mitigating devices have you found depending on the degree of imposition involved in the request?

- $\quad$ Are the interactional and contextual factors important when selecting a particular request head act and its mitigating devices?

FIGURE 1 Awareness-raising questions worksheet 
Focus on sociopragmatic features

Step 1. Circle the option you think it is appropriate:

1. Speakers' social distance: close distant very distant

2. Speakers' power: $\quad \mathrm{S}^{\star}>\mathrm{H}^{\star \star} \quad \mathrm{S}=\mathrm{H} \quad \mathrm{S}<\mathrm{H}$

3. Speaker's imposition: low mild high

Step 2. Provide the interactional and contextual factors that take place in the scenes.

Step 3. Provide additional aspects regarding their non-verbal behavior (tone of voice, body language, attitudinal behavior, facial expressions, and so on).

Focus on pragmalinguistic features

Step 4. Note down the request head acts and the mitigating devices that take place in the two scenes and consider:

1. whether they are appropriate for the given contexts.

2. whether the same request head act and its mitigating devices could be used in the two scenes.

Note: * $\mathrm{S}=$ Speaker; ${ }^{*} \mathrm{H}=$ Hearer

FIGURE 2 Film observation worksheet 